\title{
Stimulation of intestinal calcium absorption by orally administrated vitamin D3 compounds: a prospective open-label randomized trial in osteoporosis
}

\author{
K. Uenishi ${ }^{1} \cdot$ M. Tokiwa $^{2} \cdot$ S. Kato ${ }^{3,4} \cdot$ M. Shiraki $^{5}$ (D)
}

Received: 4 June 2017 / Accepted: 14 December 2017 / Published online: 23 December 2017

(C) The Author(s) 2017. This article is an open access publication

\begin{abstract}
Summary Intestinal fractional calcium absorption (FCA) was assessed before and after vitamin D3 treatment. Serum $1,25(\mathrm{OH})_{2} \mathrm{D}$ concentration was significantly increased by plain vitamin D3 and reduced by eldecalcitol. The $1 \alpha$ hydroxyl calcidiol and eldecalcitol treatments increased FCA, which may be induced through direct stimulation of vitamin D receptors in the intestine.

Introduction To assess the effects of vitamin D3 compounds on intestinal FCA and calcium-regulating hormones in postmenopausal osteoporosis, a randomized open-label prospective study was conducted.

Methods Forty eligible patients were allocated randomly into four groups: eldecalcitol (ELD; $0.75 \mu \mathrm{g} /$ day), $1 \alpha$ hydroxyl calcidiol (ALF; $1 \mu \mathrm{g} /$ day), plain vitamin D3 (800 IU/day), and control. Before and after the 4-week treatment, intestinal FCA was estimated by using a double isotope method, and serum concentrations of calcium-regulating hormones and a bone turnover marker were measured. Results The baseline FCA value of the participants was $21.5 \pm 7.9 \%$ (mean $\pm \mathrm{SD}$ ) and was significantly correlated with serum $1,25(\mathrm{OH})_{2} \mathrm{D}$ (calcitriol) concentration. After the treatment, the FCA significantly increased by $59.5 \%$ (95\% CI, 41.6 to $77.4 \%$ ) in the ELD group and by $45.9 \%$ (27.9 to $63.8 \%$ ) in the ALF group, whereas no significant change in the plain vitamin D3 group was found. Unlike the baseline FCA, post-treatment FCA exhibited no significant correlation with serum calcitriol concentration. Parathyroid hormone levels were suppressed by ALF and plain vitamin D3 but were sustained in the ELD and control groups. Serum calcitriol tended to be suppressed by ELD, whereas plain vitamin D3 treatment increased both serum 25(OH)D and calcitriol concentrations. Conclusion These findings suggest that oral administration of vitamin D3 analogues (ALF and ELD) stimulates FCA but plain vitamin D3 does not. Those effects of vitamin D3 compounds on FCA were independent of serum calcitriol concentration, suggesting that ALF and ELD may directly stimulate intestinal vitamin D receptors.
\end{abstract}

Keywords Alfacalcidol · Eldecalcitol · Intestinal calcium absorption · Plain vitamin D3 · Serum vitamin D concentration

\section{Introduction}

Sufficient calcium intake and an appropriate serum vitamin D concentration are essential factors for maintaining optimal bodily organ and system functions. However, a 2013 report of the National Nutritional Survey of Japan [1] raised concerns regarding calcium intake in the Japanese population. The mean calcium intake in Japan decreased from $585 \mathrm{mg} /$
M. Shiraki

ripid@bh.wakwak.com

K. Uenishi

uenishi@eiyo.ac.jp

M. Tokiwa

tokiwa@idd-inc.co.jp

S. Kato

shigeaki.kato@iwakimu.ac.jp
1 Division of Nutritional Physiology, Kagawa Nutrition University, Saitama, Japan

2 Clinical Development Department, IDD Inc., Tokyo, Japan

3 Center for Regional Cooperation, Iwaki Meisei University, Iwaki, Fukushima, Japan

4 Tokiwa Foundation, Research Institute of Innovative Medicine, Iwaki, Fukushima, Japan

5 Department of Internal Medicine, Research Institute and Practice for Involutional Diseases, 1610-1 Meisei, Misato, Azumino, Nagano 399-8101, Japan 
day in 1995 to less than $500 \mathrm{mg} /$ day in 2013 . We previously investigated the estimated average requirement (EAR) of calcium in Japanese post-menopausal women aged $62-77$ years by evaluating their calcium balance. The results showed that the EAR was $788 \mathrm{mg} /$ day in these women [2]. Thus, the current mean calcium intake in Japan is far lower than the EAR. In addition to the low calcium intake, there is a considerably high rate of vitamin D deficiency in individuals with osteoporosis [3] as well as among post-menopausal women [4]. For these reasons, measures should be taken to prevent low calcium intake and vitamin D deficiency.

Low calcium intake leads to an adaptive mechanism that increases the calcium absorption rate in the intestines to maintain a proper calcium balance. However, this adaptive ability decreases with age $[5,6]$, which has been explained partly by the deterioration of vitamin $\mathrm{D}$ activation [7]. To correct calcium and vitamin $\mathrm{D}$ malnutrition, vitamin $\mathrm{D} 3$ analogues such as $1 \alpha(\mathrm{OH}) \mathrm{D} 3$ (alfacalcidol, ALF) and $1 \alpha, 25$-dihydoxy-2 $\beta$-(2hydroxypropyloxy) vitamin D3 (eldecalcitol, ELD) are approved and widely used for the treatment of osteoporosis in Japan, because these vitamin D3 compounds are believed to stimulate intestinal calcium absorption. Plain vitamin D3 has been used in Western countries, and its administration is mainly aimed at correcting vitamin D deficiency.

Calcium is absorbed from food in the intestine by active and passive transport systems. The active transport of calcium, which is the main process of calcium absorption, is regulated by the biologically active form of vitamin $\mathrm{D}, 1,25(\mathrm{OH})_{2} \mathrm{D}$ (calcitriol) [5], through activation of vitamin D receptors (VDRs). Recent studies of calcium absorption mechanisms in the intestine identified the human brush-border membrane calcium channel to be TRPV6. Absorbed calcium is subsequently buffered in the cytoplasm by calbindin-D9k and extruded from the cell via basolateral membrane $\mathrm{Ca}^{2+}$ ATPase, PMCA1 [8]. Incubation of duodenal cells with calcitriol and $25(\mathrm{OH}) \mathrm{D}$ revealed that both treatments induced TRPV6 expression [9]. The responses of TRPV6 to 25(OH) D3 were significantly associated with expression of CYP27B1 [9], suggesting that $25(\mathrm{OH}) \mathrm{D} 3$ may be converted to calcitriol in the duodenal cells. In this experiment, CYP24 transcripts were detected after incubation with either metabolite, suggesting that activation of $25(\mathrm{OH}) \mathrm{D} 3$ to calcitriol is followed by catabolism in the cells [9]. A comparative study between calcitriol and ELD in mice concluded that ELD stimulated the expression of target genes in the kidneys and bone much less than did calcitriol. However, stimulation of target genes in the intestine by oral administration of ELD was comparable to that of calcitriol [10]. Another study examined the effects of oral administration of ELD and calcitriol on intestinal calcium absorption in rats; calcium absorption was enhanced more potently in the ELD group than in the calcitriol group [11].

These observations raise the question of why the biological behavior of ELD in the intestine is different from that in other organs. The intestine is exposed to $10^{-6} \mathrm{~mol}$ of vitamin D3 compounds when administered orally, whereas other organs are exposed to $10^{-12} \mathrm{~mol}$ of calcitriol, which is supplied by the blood stream. In addition to the high vitamin D3 exposure when given orally, hepato-intestinal circulation may also play a role in intestinal calcium absorption. Therefore, the biological activities of orally administered vitamin D3 compounds are expected to be clearer when measured in the intestine than in the other internal organs, such as bone and kidney.

However, no data regarding the effect of ELD and ALF on intestinal calcium absorption in humans are available. Therefore, in the present study, we investigated the effect of serum concentration of calcitriol on intestinal calcium absorption in post-menopausal osteoporosis patients using a double isotope method [12-14]. In addition, we investigated the effects of oral doses of vitamin D3 compounds on intestinal calcium absorption and its effects on other internal organs, such as bone, parathyroid glands, and kidney.

Here, we demonstrate significant stimulation of intestinal calcium absorption by oral administration of ALF and ELD, but not by plain Vit $\mathrm{D}$, and discuss the possible mechanisms behind this.

\section{Materials and methods}

\section{Study design and participants}

We conducted a randomized, open-label, controlled singlecenter clinical trial to assess the effects of vitamin D3 compounds on osteoporosis. The primary objective was quantitative assessment of intestinal fractional calcium absorption (FCA) using a double isotope method [12-14]. We compared changes in FCA among patients randomly allocated to receive $\operatorname{ELD}(0.75 \mu \mathrm{g} /$ day $), \operatorname{ALF}(1 \mu \mathrm{g} /$ day $)$, plain vitamin D3 (800 IU/day), or no vitamin D3 analogue (control). The administered doses of ELD and ALF were those approved for osteoporosis in Japan. This study was conducted between December 2015 and March 2016; the winter season was selected to minimize sunshine exposure.

Subjects were post-menopausal osteoporosis patients with a major osteoporotic fracture risk between 10 and 25\% according to the Fracture Risk Assessment Tool [15]. Patients were excluded if they had a major osteoporotic fracture within 1 year, had a history of endocrine diseases, were receiving drugs with potential effects on bone metabolism and urolithiasis, had a history of denosumab treatment, had received bisphosphonate treatment within 6 months, or had received teriparatide injection within 4 weeks prior to the study. Patients were also excluded if they had hyper- or hypocalcemia, hypercalciuria ( $>0.4 \mathrm{mg} / \mathrm{dL}$ GF), or chronic kidney disease $\left(\mathrm{eGFR}<30 \mathrm{~mL} / \mathrm{min} / 1.73 \mathrm{~m}^{2}\right)$. 


\section{Ethical considerations}

This study was conducted in compliance with the Ethical Guidelines for Medical and Health Research Involving Human Subjects of Japan under the Declaration of Helsinki. The study protocol was approved by the Ethical Committee of Keikokai Medical Corporation P-one Clinic (Tokyo, Japan) and was registered in the University Hospital Medical Information Network of Japan under the identifier UMIN000024492. The investigators explained the study procedures verbally, and written informed consent was obtained from each participant before the study.

\section{Study procedures}

The subjects visited the study site on three occasions. At the first visit, subjects provided written informed consent and their health status was evaluated to confirm eligibility. Subjects completed a diet questionnaire of intake frequency of foods based on the previous week. According to the responses, habitual calcium intake was estimated.

Within 4 weeks after the first visit, eligible subjects were hospitalized at the study site (Keikokai Medical Corporation P-one Clinic) to be measured for baseline intestinal FCA and undergo other laboratory tests related to calcium and phosphorus metabolism; they were also randomly allocated to a study group. The morning following hospitalization, urine was collected at the second urination of the day.

The subjects were provided exactly the same experimental diet, which contained $423 \mathrm{mg} /$ day of calcium. In addition, $300 \mathrm{mg}$ of calcium from calcium carbonate including ${ }^{44} \mathrm{Ca}$ was also given orally. Therefore, the total amount of calcium intake at baseline and the end of the study was $723 \mathrm{mg} /$ day. Fifteen minutes after the calcium carbonate administration, $3 \mathrm{mg}$ of ${ }^{42} \mathrm{Ca}$ was intravenously injected, as a calcium chloride solution. ${ }^{42} \mathrm{Ca}$ and ${ }^{44} \mathrm{Ca}$ were purchased from Trace Sciences International Corp. (Ontario, Canada). Urine was then collected for $24 \mathrm{~h}$, and specimens for analysis of stable isotopes were adjusted by the Division of Nutritional Physiology of Kagawa Nutrition University in accordance with the method of Patterson et al. [16]. Inductively coupled plasma mass spectrometry (Agilent $7500 \mathrm{cs}$, Agilent Technologies, Inc., Tokyo, Japan) was used to measure ${ }^{42} \mathrm{Ca},{ }^{43} \mathrm{Ca}$, and ${ }^{44} \mathrm{Ca}$. Total calcium in urine was measured with inductively coupled plasma atomic emission spectroscopy (720ES, Agilent Technologies, Inc.) by the Analysis Research Laboratory, Mitsui Chemical Analysis and Consulting Service, Inc. (Chiba, Japan). The coefficient of variation (CV) for the measurement of stable calcium isotopes was $<2 \%$.

Collected blood samples were tested for 25(OH)D $(\mathrm{CV}<$ $12.09 \%$ ) by radioimmunoassay (RIA; 25 -hydroxyvitamin D

${ }^{125}$ I RIA Kit, DiaSorin Inc., Stillwater, MN, USA), $1,25(\mathrm{OH})_{2} \mathrm{D}(\mathrm{CV}<14.5 \%)$ by RIA $\left(1,25(\mathrm{OH})_{2} \mathrm{D}\right.$ RIA kit, DiaSorin) [17], and parathyroid hormone $(\mathrm{CV}<2.94 \%)$ by high-sensitivity RIA (LSIM, Tokyo, Japan). Serum calcium, phosphate, albumin, and creatinine concentrations were also measured. Urinary N-terminal telopeptides of type 1 collagen (NTx; CV $<6.70 \%$ ) was measured by using an NTx urine ELISA (Osteomark, Alere Inc., Waltham, MA, USA). All biochemical measurements were carried out at the same laboratory (SRL, Tokyo, Japan).

Following the baseline measurement of FCA, subjects were randomly allocated into four groups: ELD treatment, ALF treatment, plain vitamin D3 treatment, and no treatment (control). An independent research secretariat randomly allocated eligible subjects to one of three treatment groups or the control group by means of computer-generated randomization codes stratified by the calcium intake values calculated from the diet questionnaires completed at the first visit. ELD, ALF, or plain vitamin D3 was taken orally after breakfast for 27 days. ELD and ALF were purchased from Chugai Pharmaceutical Co. (Tokyo, Japan) and plain vitamin D3 was purchased from Otsuka Pharmaceutical Co. (Tokushima, Japan).

Subjects retuned to the study site for their third visit 4 weeks after the first treatment, when they were hospitalized to undergo the FCA measurements. During those 4 weeks, participants were prohibited from taking any calcium supplements. The last blood and urine samples were collected the day following the third visit. Double isotopes were administered after the final administration of ELD, ALF, or plain vitamin D3.

Stable calcium isotope preparations for FCA measurement were adjusted by the Department of Pharmacy, Kobe University Hospital (Hyogo, Japan) and formulated for personal use by the Otsu Pharmaceuticals Plant, Toyobo Co., Ltd. (Shiga, Japan) following Japanese regulations of good manufacturing practice. Regular pharmaceutical tests for drugs intended for administration to human subjects were conducted by the manufacturing plant and Hatano Research Institute, Food and Drug Safety Center (Kanagawa, Japan), and all the test results met the standards for human use.

\section{Fractional calcium absorption calculation}

FCA was calculated using the formula proposed by Eastell et al. [13]:

$\mathrm{FCA}=\frac{\Delta \% \text { excess }{ }^{44} \mathrm{Ca}}{\Delta \% \text { excess }{ }^{42} \mathrm{Ca}} \times \frac{\text { natural abundance }{ }^{44} \mathrm{Ca}}{\text { natural abundance }{ }^{42} \mathrm{Ca}} \times \frac{\text { dose }^{42} \mathrm{Ca}}{\text { dose }^{44} \mathrm{Ca}} \times 100 \%$

where

$$
\begin{aligned}
& \Delta \% \text { excess }{ }^{44} \mathrm{Ca} \\
& =\frac{\text { observed }{ }^{44} \mathrm{Ca} /{ }^{43} \mathrm{Ca}-\text { natural abundance }{ }^{44} \mathrm{Ca} /{ }^{43} \mathrm{Ca}}{\text { natural abundance }{ }^{44} \mathrm{Ca} /{ }^{43} \mathrm{Ca}} \\
& \quad \times 100 \%
\end{aligned}
$$




$$
\begin{aligned}
& \Delta \% \text { excess }{ }^{42} \mathrm{Ca} \\
& =\frac{\text { observed }{ }^{42} \mathrm{Ca} /{ }^{43} \mathrm{Ca}-\text { natural abundance }{ }^{42} \mathrm{Ca} /{ }^{43} \mathrm{Ca}}{\text { natural abundance }{ }^{42} \mathrm{Ca} /{ }^{43} \mathrm{Ca}} \\
& \quad \times 100 \%
\end{aligned}
$$

\section{Statistical analyses}

The necessary sample size was calculated based on previous data showing that healthy participants had a $71.8 \%$ change in FCA from baseline with a 1-week treatment of high-dose calcitriol [14]. Assuming a power of $90 \%$, a standard deviation of $50 \%$, and a two-sided significance level of $5 \%$, a sample size of eight subjects per group was planned. Given the anticipated withdrawal rate of 20\%, 10 participants were enrolled per group.

Efficacy and safety analyses were conducted according to a pre-specified statistical analysis plan. The per protocol set excluded subjects with missing FCA data after treatment and those with drug compliance less than $75 \%$. The per protocol set was used for the primary analyses comprising evaluation of the effect of ELD on intestinal calcium absorption, percentage change from baseline FCA, and comparisons between baseline and post-treatment FCA using paired $t$ test. The secondary analysis was a comparison of the percentage change from baseline FCA among groups using ANCOVA with factors for treatment and Tukey's multiple comparison test.

In the analyses of treatment effects of vitamin D3 compounds on calcium regulation, changes in calcium-regulating hormones and bone turnover marker concentrations were calculated as changes in absolute value from the value after the 4-week treatment minus the baseline value. To determine the factors contributing to FCA, multivariate regression analysis was performed.

\section{Results}

Forty patients with post-menopausal osteoporosis were enrolled in the study and randomly allocated into four study groups. Baseline data, including intestinal FCA, were obtained for all 40 subjects. Final data for 38 subjects were available for pre- and post-treatment comparisons. One participant each in the ELD and ALF groups discontinued the study; their reasons for discontinuation were not related to adverse events associated with the test drugs.

The background data of the subjects were well balanced among the groups (Table 1). The mean calcium intake of the participants $(558 \mathrm{mg} /$ day) was similar to that in the National Nutritional Survey of Japan (http://www.mhlw.go.jp/file/04H o u d o u hap p y o u - 10904750 - K e n k o u k y o k u Gantaisakukenkouzoushinka/kekkagaiyou.pdf), in which the mean daily calcium intake for individuals in their sixties and seventies was reported to be 560 and $557 \mathrm{mg} /$ day, respectively.
Although none of the subjects had severe vitamin D deficiency $(25(\mathrm{OH}) \mathrm{D} \leq 10 \mathrm{ng} / \mathrm{mL}), 15(37.5 \%)$ had mild vitamin $\mathrm{D}$ deficiency $(10 \mathrm{ng} / \mathrm{ml}<25(\mathrm{OH}) \mathrm{D}<20 \mathrm{ng} / \mathrm{mL})$.

The FCA values at baseline ranged from 19.1 to $22.7 \%$ and were not significantly different among the groups. Serum concentration of calcitriol $\left(R^{2}=0.180, p=0.008\right)$, blood urea nitrogen (BUN; $\left.R^{2}=0.144, p=0.019\right)$, and urinary excretion of calcium $\left(R^{2}=0.329, p=0.0002\right)$ were significantly correlated with baseline FCA in a univariate linear regression model (Table 2). Neither daily consumption of calcium estimated by the diet questionnaire nor serum concentration of $25(\mathrm{OH}) \mathrm{D}$ at baseline was correlated with baseline FCA. The stepwise multivariate linear regression analysis for baseline FCA indicated that serum concentrations of calcitriol and BUN and urinary calcium excretion were independent determinants of FCA (Table 3).

After the 4-week treatment, changes in serum and urinary parameters were examined (Table 4). Urinary excretion of NTx was significantly decreased by ELD treatment, as compared with that in the control and plain vitamin D3 groups. Serum concentration of $25(\mathrm{OH}) \mathrm{D}$ was significantly increased by plain vitamin D3 treatment, as compared with that in other groups. After the plain vitamin D3 treatment, none of the subjects were vitamin D deficient. Serum concentration of calcitriol in the ELD group decreased, whereas that in the plain vitamin D3 group increased $(p=0.0112)$. As compared with the control group, urinary excretion of calcium was increased both by ELD and ALF treatments. The serum concentration of PTH was decreased by $-21.6 \pm 12.5 \%$ from the baseline value after $\operatorname{ALF}$ treatment ( $p=0.0015$ by paired $t$ test).

After the 4-week treatment, the FCA values were $33.7 \pm 4.6$, $30.2 \pm 9.5,24.7 \pm 8.6$, and $20.4 \pm 6.5 \%$ in the ELD, ALF, plain vitamin D3, and control groups, respectively (Table 5). The FCA values in the ELD and the ALF groups were significantly higher than the baseline FCA values $(p<0.0001$ for ELD and $p=0.0029$ for ALF in paired $t$ test). These represent increases of $59.5 \%$ (95\% CI, 41.6 to $77.4 \%$ ) for ELD, $45.9 \%$ (27.9 to $63.8 \%$ ) for ALF, $16.7 \%$ ( -0.2 to $33.7 \%$ ) for plain vitamin D3, and $5.2 \%$ (-12.0 to $22.3 \%$ ) for control groups (Table 5). The percentage increase in FCA at post-treatment in the ELD and the ALF groups were significantly higher than those in the plain vitamin D3 and control groups; those in the ELD and ALF groups, and in the plain vitamin D3 and control groups were similar. The FCA values at baseline were significantly correlated with the baseline serum concentration of calcitriol (Fig. 1A), but post-treatment FCA was not correlated with posttreatment serum concentrations of calcitriol (Fig. 1B).

\section{Discussion}

The baseline characteristics of the four groups indicate that the randomization process in the present study was successful. 
Table 1 Demographic and clinical characteristics of patients

\begin{tabular}{|c|c|c|c|c|c|c|}
\hline Characteristic & $\operatorname{ELD}(n=9)$ & $\operatorname{ALF}(n=9)$ & Plain vitamin $\mathrm{D}_{3}(n=10)$ & Control $(n=10)$ & Total $(n=38)$ & $p$ value $^{\mathrm{a}}$ \\
\hline Age (years) & $74.2 \pm 2.4$ & $75.0 \pm 3.0$ & $72.9 \pm 3.1$ & $74.6 \pm 3.0$ & $74.2 \pm 2.9$ & 0.4215 \\
\hline Years after menopause & $22.6 \pm 3.8$ & $26.0 \pm 4.6$ & $23.2 \pm 6.7$ & $23.2 \pm 4.5$ & $23.7 \pm 5.0$ & 0.3979 \\
\hline 10 -Year fracture probability $(\%)^{\mathrm{b}}$ & $14.7 \pm 2.6$ & $15.6 \pm 3.7$ & $15.1 \pm 4.0$ & $16.5 \pm 3.6$ & $15.5 \pm 3.5$ & 0.7015 \\
\hline Height $(\mathrm{cm})$ & $151.23 \pm 2.99$ & $150.71 \pm 4.78$ & $153.70 \pm 5.31$ & $151.71 \pm 6.07$ & $151.88 \pm 4.90$ & 0.5777 \\
\hline Weight (kg) & $54.34 \pm 8.38$ & $55.40 \pm 7.18$ & $48.32 \pm 5.89$ & $51.96 \pm 7.01$ & $52.38 \pm 7.38$ & 0.1555 \\
\hline Serum albumin $(\mathrm{g} / \mathrm{dL})$ & $4.40 \pm 0.30$ & $4.31 \pm 0.20$ & $4.53 \pm 0.31$ & $4.41 \pm 0.14$ & $4.42 \pm 0.25$ & 0.3026 \\
\hline Serum creatinine $(\mathrm{mg} / \mathrm{dL})$ & $0.608 \pm 0.101$ & $0.609 \pm 0.056$ & $0.568 \pm 0.039$ & $0.581 \pm 0.067$ & $0.591 \pm 0.068$ & 0.4894 \\
\hline uNTX (nmol BCE/mmol Cre) & $36.9 \pm 15.3$ & $47.7 \pm 18.6$ & $52.6 \pm 32.6$ & $45.9 \pm 9.1$ & $46.0 \pm 20.9$ & 0.4438 \\
\hline $25(\mathrm{OH}) \mathrm{D}(\mathrm{ng} / \mathrm{mL})$ & $24.7 \pm 9.7$ & $20.0 \pm 5.1$ & $23.9 \pm 5.6$ & $21.3 \pm 5.2$ & $22.5 \pm 6.7$ & 0.4348 \\
\hline Calcitriol (pg/mL) & $59.7 \pm 15.6$ & $50.8 \pm 18.4$ & $46.6 \pm 11.5$ & $60.9 \pm 15.9$ & $54.5 \pm 6.1$ & 0.1383 \\
\hline PTH (pg/mL) & $60 \pm 15$ & $57 \pm 17$ & $55 \pm 13$ & $52 \pm 18$ & $56 \pm 16$ & 0.7551 \\
\hline Corrected serum $\mathrm{Ca}(\mathrm{mg} / \mathrm{dL})$ & $9.3 \pm 0.2$ & $9.3 \pm 0.3$ & $9.1 \pm 0.3$ & $9.3 \pm 0.2$ & $9.2 \pm 0.2$ & 0.3957 \\
\hline Serum P (mg/dL) & $3.6 \pm 0.4$ & $3.7 \pm 0.3$ & $3.5 \pm 0.4$ & $3.7 \pm 0.3$ & $3.6 \pm 0.4$ & 0.6088 \\
\hline Corrected urinary $\mathrm{Ca}(\mathrm{mg} / \mathrm{dL} \mathrm{GF})$ & $0.08 \pm 0.03$ & $0.07 \pm 0.04$ & $0.09 \pm 0.03$ & $0.06 \pm 0.03$ & $0.08 \pm 0.04$ & 0.3062 \\
\hline Corrected urinary $\mathrm{P}$ (mg/dL GF) & $0.39 \pm 0.008$ & $0.37 \pm 0.08$ & $0.41 \pm 0.11$ & $0.35 \pm 0.08$ & $0.38 \pm 0.09$ & 0.4811 \\
\hline Blood urea nitrogen (mg/dL) & $12.9 \pm 2.6$ & $13.6 \pm 2.6$ & $13.6 \pm 2.5$ & $14.6 \pm 2.2$ & $13.7 \pm 2.5$ & 0.4985 \\
\hline eGFR (mL/min/1.73m²) & $73.9 \pm 13.7$ & $72.1 \pm 7.8$ & $78.1 \pm 5.9$ & $76.3 \pm 9.3$ & $75.2 \pm 9.4$ & 0.5458 \\
\hline Habitual Ca intake $(\mathrm{mg} / \text { day })^{\mathrm{c}}$ & $574.6 \pm 121.0$ & $553.9 \pm 109.6$ & $575.7 \pm 202.7$ & $529.4 \pm 117.3$ & $558.1 \pm 139.6$ & 0.8795 \\
\hline
\end{tabular}

${ }^{\mathrm{a}}$ The difference among the treatment groups was analyzed by one-way ANOVA

${ }^{b}$ The 10-year probability of major osteoporotic fracture was assessed by the Japanese version of FRAX

${ }^{\mathrm{c}}$ Calcium intake before the entry was evaluated by a diet questionnaire of frequency of foods intake

Data are expressed as the mean $\pm \mathrm{SD}$

Abbreviations: Ca, calcium; ELD, eldecalcitol; ALF, alfacalcidol; uNTX, urinary N-terminal telopeptides; BCE, bone collagen equivalent; Cre, creatinine; PTH, intact parathyroid hormone; GF, glomerular filtration; eGFR, estimated glomerular filtration rate

The intestinal FCA values measured by using the double isotope method ranged from 19.1 to $22.7 \%$, with no statistical difference among the groups, and these values are comparable to those in previous reports [18-20]. The habitual calcium intake levels (mean, $558 \mathrm{mg} /$ day) in our study population were within the range of previously reported dietary calcium intake [18-20] and were similar to the values of subjects of similar ages reported by the National Nutritional Survey of Japan (http://www.mhlw.go.jp/file/04-Houdouhappyou-10904750Kenkoukyoku-Gantaisakukenkouzoushinka/kekkagaiyou. pdf). Furthermore, it appears unlikely that the participants were suffering from severe vitamin D deficiency. However, $37.5 \%$ of patients had mild vitamin D deficiency $(10 \mathrm{ng} / \mathrm{ml}<$ $25(\mathrm{OH}) \mathrm{D}<20 \mathrm{ng} / \mathrm{mL})$.

Univariate regression analysis showed that the baseline FCA was significantly correlated with the baseline urinary excretion of calcium and serum concentrations of BUN and calcitriol, but not with serum $25(\mathrm{OH}) \mathrm{D}$ concentration. Although Heaney et al. [20] reported an inverse relationship between intestinal FCA and dietary calcium intake, no such relationship was observed in our study (Table 2), presumably owing to the small variability of calcium intake in the study population. Multivariate analysis revealed that serum concentrations of BUN and calcitriol, as well as urinary excretion of calcium, were significant independent determinants of baseline FCA (Table 3). The urinary excretion of calcium may be a reflection of FCA, but not a regulator of FCA.

All of these findings support the idea that calcitriol is the most potent stimulator of intestinal calcium absorption. Because the kidneys are the primary organ to convert 25(OH)D to calcitriol, acting locally, we expected an inverse correlation of BUN and serum calcitriol level. However, further stepwise analysis revealed that BUN and calcitriol levels were not associated (data not shown). One possible explanation is that the kidneys were not fully functional in regulating calcium homeostasis. In fact, $88 \%$ of the subjects in this study had stage 2 chronic kidney disease, suggesting that the renal state of the present population was mildly dysfunctional, which would account for the lack of relationship between BUN and serum calcitriol levels. Renal function in elderly people is sometimes difficult to assess: serum concentrations of BUN and creatinine are frequently dissociated because of dehydration (even to a mild extent); eGFR is strongly affected by age; and creatinine concentration is affected by muscle mass, which is low in osteoporosis patients.

Interestingly, in all four groups, post-treatment serum concentrations of calcitriol had no significant correlation with intestinal FCA (Fig. 1B). The FCA was remarkably 
Table 2 Univariate linear regression model of baseline FCA

\begin{tabular}{lllll}
\hline Independent variable & Regression coefficient & SE & $R^{2}$ & $p$ value \\
\hline uNTX (nmol BCE/mmol Cre) & 0.066 & 0.062 & 0.0306 & 0.2938 \\
25(OH)D (ng/mL) & -0.057 & 0.191 & 0.0024 & 0.7680 \\
Calcitriol (pg/mL) & 0.208 & 0.074 & 0.1796 & 0.0080 \\
PTH (pg/mL) & 0.082 & 0.083 & 0.0265 & 0.3288 \\
Corrected serum Ca (mg/dL) & -1.649 & 5.503 & 0.0025 & 0.7661 \\
Serum P (mg/dL) & -5.110 & 3.538 & 0.0548 & 0.1574 \\
Corrected urinary Ca (mg/dL GF) & 127.819 & 30.402 & 0.3293 & 0.0002 \\
Corrected urinary P (mg/dL GF) & -13.835 & 14.871 & 0.0235 & 0.3584 \\
Age (years) & 0.016 & 0.453 & 0.0000 & 0.9726 \\
Years after menopause & 0.078 & 0.261 & 0.0025 & 0.7677 \\
10-year fracture probability (\%) & -0.298 & 0.375 & 0.0172 & 0.4324 \\
Habitual Ca intake (mg/day) & -0.002 & 0.009 & 0.0009 & 0.8609 \\
Height (cm) & 0.222 & 0.265 & 0.0192 & 0.4069 \\
Weight (kg) & 0.338 & 0.169 & 0.1005 & 0.0524 \\
Total protein (g/dL) & -4.799 & 3.388 & 0.0528 & 0.1652 \\
Albumin (g/dL) & 1.677 & 5.237 & 0.0028 & 0.7506 \\
Blood urea nitrogen (mg/dL) & -1.236 & 0.502 & 0.1442 & 0.0187 \\
eGFR (mL/min/1.73m ${ }^{\mathrm{b}}$ ) & 0.023 & 0.139 & 0.0008 & 0.8669 \\
\hline
\end{tabular}

Each independent variable was baseline value

${ }^{\mathrm{a}}$ The 10-year probability of major osteoporotic fracture was assessed by FRAX Japanese version

${ }^{\mathrm{b}}$ Calcium intake before the entry was evaluated by diet questionnaire

Abbreviations: Ca, calcium; FCA, fractional Ca absorption rate; uNTX, urinary N-terminal telopeptides; BCE, bone collagen equivalent; Cre, creatinine; PTH, intact parathyroid hormone; GF, glomerular filtration; eGFR, estimated glomerular filtration rate potentiated by treatment with ELD or ALF (Table 5), but the serum concentrations of calcitriol tended to be decreased by ELD treatment (from $59.7 \pm 15.6$ to $46.1 \pm 22.4 \mathrm{pg} / \mathrm{mL}, p=$ 0.0539 , paired $t$ test) and slightly increased by ALF treatment (from $50.8 \pm 18.4$ to $57.5 \pm 18.5 \mathrm{pg} / \mathrm{mL}, p=0.2084$ ). In the plain vitamin D3 group, serum concentrations of calcitriol were significantly increased from $46.6 \pm 11.5$ to $63.6 \pm$ $12.0 \mathrm{pg} / \mathrm{mL}(p=0.0085)$. These relationships between serum concentration of calcitriol and intestinal FCA among various vitamin D3 compounds were quite variable. Given the increased FCA, intestinal VDRs appeared to be activated by direct binding of ELD $(0.75 \mu \mathrm{g})$ or ALF $(1.0 \mu \mathrm{g})$, exerting calcemic function, despite these analogues having a lower VDR binding affinity than that of calcitriol. The chemical structure of ELD consists of two carbon-bearing hydroxyl groups at the $1 \alpha$ and 25 positions. Since these two hydroxyl groups are essential for the binding to VDR, orally administrated ELD may bind to intestinal VDR directly. This is a possible explanation why the FCA was enhanced by ELD despite a reduction in serum concentration of calcitriol.

The mode(s) of action of ALF on FCA seems to be more complicated. The slightly increased concentration of serum
Table 3 Stepwise multivariate linear regression model of baseline FCA

\begin{tabular}{lllll}
\hline Independent variable & Regression coefficient & SE & $\begin{array}{l}\text { Standard partial } \\
\text { regression coefficient }\end{array}$ & $p$ value \\
\hline Calcitriol $(\mathrm{pg} / \mathrm{mL})$ & 0.187 & 0.052 & 0.383 & 0.0011 \\
Serum P (mg/dL) & -3.944 & 2.356 & -0.181 & 0.1038 \\
Corrected urinary Ca (mg/dL GF) & 107.769 & 24.307 & 0.484 & 0.0001 \\
Total protein (g/dL) & -3.721 & 2.286 & -0.178 & 0.1134 \\
Blood urea nitrogen (mg/dL) & -0.995 & 0.358 & -0.306 & 0.0090 \\
\hline
\end{tabular}

The $R^{2}$ for this model is 0.6392 . Each independent variable was baseline value. Serum concentrations of calcitriol and blood urea nitrogen and urinary excretion of calcium were independent significant determinants of FCA at baseline

Abbreviations: Ca, calcium; FCA, fractional Ca absorption rate; GF, glomerular filtration 
Table 4 Changes in calcium regulating hormones and bone resorption before and after the treatment

\begin{tabular}{|c|c|c|c|c|c|c|c|c|c|c|c|}
\hline & & \multicolumn{4}{|l|}{ Treatment } & \multicolumn{6}{|c|}{$p$ value $^{\mathrm{a}}$} \\
\hline & & \multirow[t]{2}{*}{ Control } & \multirow[t]{2}{*}{ ELD } & \multirow[t]{2}{*}{ ALF } & \multirow[t]{2}{*}{$\begin{array}{l}\text { Plain } \\
\text { vitamin } \mathrm{D}_{3}\end{array}$} & \multicolumn{3}{|c|}{ Control vs } & \multicolumn{2}{|c|}{$\begin{array}{l}\text { Plain vitamin } \\
\mathrm{D}_{3} \text { vs }\end{array}$} & \multirow{2}{*}{$\begin{array}{l}\text { ALF vs } \\
\text { ELD }\end{array}$} \\
\hline & & & & & & ELD & ALF & $\begin{array}{l}\text { Plain } \\
\text { vitamin } \mathrm{D}_{3}\end{array}$ & ELD & ALF & \\
\hline $\begin{array}{l}\text { uNTX } \\
\quad \text { (nmol BCE/mmol Cre) }\end{array}$ & $\begin{array}{l}\text { Actual } \\
\text { Change }\end{array}$ & $\begin{array}{l}52.4 \pm 12.8 \\
6.5 \pm 11.5\end{array}$ & $\begin{array}{l}31.0 \pm 10.6 \\
-5.9 \pm 8.1\end{array}$ & $\begin{array}{l}48.5 \pm 20.6 \\
0.8 \pm 11.9\end{array}$ & $\begin{array}{l}56.0 \pm 27.4 \\
3.4 \pm 9.1\end{array}$ & 0.0151 & NS & NS & 0.0451 & NS & NS \\
\hline $25(\mathrm{OH}) \mathrm{D}(\mathrm{ng} / \mathrm{mL})$ & $\begin{array}{l}\text { Actual } \\
\text { Change }\end{array}$ & $\begin{array}{l}24 \pm 9 \\
3 \pm 5\end{array}$ & $\begin{array}{l}27 \pm 10 \\
2 \pm 3\end{array}$ & $\begin{array}{l}23 \pm 9 \\
3 \pm 6\end{array}$ & $\begin{array}{l}37 \pm 6 \\
13 \pm 5^{b}\end{array}$ & NS & NS & 0.0007 & 0.0004 & 0.0006 & NS \\
\hline $\begin{array}{l}\text { Calcitriol } \\
(\mathrm{pg} / \mathrm{mL})\end{array}$ & $\begin{array}{l}\text { Actual } \\
\text { Change }\end{array}$ & $\begin{array}{l}61.7 \pm 19.6 \\
0.8 \pm 18.0\end{array}$ & $\begin{array}{l}46.1 \pm 22.4 \\
-13.7 \pm 18.1\end{array}$ & $\begin{array}{l}57.5 \pm 18.5 \\
6.8 \pm 14.8\end{array}$ & $\begin{array}{l}63.6 \pm 12.0 \\
17.0 \pm 16.0^{b}\end{array}$ & NS & NS & NS & 0.0112 & NS & NS \\
\hline PTH $(\mathrm{pg} / \mathrm{mL})$ & $\begin{array}{l}\text { Actual } \\
\text { Change }\end{array}$ & $\begin{array}{l}50 \pm 11 \\
-2 \pm 11\end{array}$ & $\begin{array}{l}54 \pm 14 \\
-6 \pm 16\end{array}$ & $\begin{array}{l}45 \pm 16 \\
-12 \pm 8^{b}\end{array}$ & $\begin{array}{l}50 \pm 12 \\
-5 \pm 6^{\mathrm{c}}\end{array}$ & NS & NS & NS & NS & NS & NS \\
\hline $\begin{array}{l}\text { Corrected serum } \\
\mathrm{Ca}(\mathrm{mg} / \mathrm{dL})\end{array}$ & $\begin{array}{l}\text { Actual } \\
\text { Change }\end{array}$ & $\begin{array}{l}9.0 \pm 0.2 \\
-0.3 \pm 0.2^{\mathrm{b}}\end{array}$ & $\begin{array}{l}9.1 \pm 0.2 \\
-0.2 \pm 0.2^{\mathrm{b}}\end{array}$ & $\begin{array}{l}9.1 \pm 0.3 \\
-0.2 \pm 0.3^{\mathrm{c}}\end{array}$ & $\begin{array}{l}9.0 \pm 0.2 \\
-0.2 \pm 0.2^{\mathrm{c}}\end{array}$ & NS & NS & NS & NS & NS & NS \\
\hline Serum P (mg/dL) & $\begin{array}{l}\text { Actual } \\
\text { Change }\end{array}$ & $\begin{array}{l}3.7 \pm 0.2 \\
0.0 \pm 0.3\end{array}$ & $\begin{array}{l}3.6 \pm 0.4 \\
0.0 \pm 0.2\end{array}$ & $\begin{array}{l}3.5 \pm 0.4 \\
-0.2 \pm 0.3\end{array}$ & $\begin{array}{l}3.6 \pm 0.3 \\
0.1 \pm 0.3\end{array}$ & NS & NS & NS & NS & NS & NS \\
\hline $\begin{array}{l}\text { Corrected urinary } \mathrm{Ca} \\
(\mathrm{mg} / \mathrm{dL} \mathrm{GF})\end{array}$ & $\begin{array}{l}\text { Actual } \\
\text { Change }\end{array}$ & $\begin{array}{l}0.06 \pm 0.03 \\
0.00 \pm 0.02\end{array}$ & $\begin{array}{l}0.11 \pm 0.04 \\
0.04 \pm 0.04^{\mathrm{c}}\end{array}$ & $\begin{array}{l}0.11 \pm 0.05 \\
0.04 \pm 0.02^{b}\end{array}$ & $\begin{array}{l}0.10 \pm 0.04 \\
0.01 \pm 0.02\end{array}$ & 0.0060 & 0.0021 & NS & NS & NS & NS \\
\hline $\begin{array}{l}\text { Corrected urinary } P \\
(\mathrm{mg} / \mathrm{dL} \text { GF })\end{array}$ & $\begin{array}{l}\text { Actual } \\
\text { Change }\end{array}$ & $\begin{array}{l}0.40 \pm 0.09 \\
0.04 \pm 0.08\end{array}$ & $\begin{array}{l}0.48 \pm 0.10 \\
0.08 \pm 0.10^{\mathrm{c}}\end{array}$ & $\begin{array}{l}0.42 \pm 0.10 \\
0.05 \pm 0.10\end{array}$ & $\begin{array}{l}0.42 \pm 0.07 \\
0.01 \pm 0.09\end{array}$ & NS & NS & NS & NS & NS & NS \\
\hline
\end{tabular}

The data are expressed as actual value (upper line) and changes from baseline value after one-month treatment (lower line)

a $p$ value was assessed using ANCOVA with factors for mode of treatment and Tukey's multiple comparison test. NS means not significant

${ }^{\mathrm{b}} p$ value was assessed using paired $t$ test, $p<0.01$

${ }^{\mathrm{c}} p<0.05$

Abbreviations: Ca, calcium; ELD, eldecalcitol; ALF, alfacalcidol; FCA, fractional Ca absorption rate; uNTX, urinary N-terminal telopeptides; BCE, bone collagen equivalent; Cre, creatinine; $\mathrm{PTH}$, intact parathyroid hormone; GF, glomerular filtration; NS, not significant

calcitriol in the ALF group (Table 4) suggests that intestinal action of calcitriol converted in the liver by CYP2R1 and CYP27A1 from ALF may bind to intestinal VDR through entero-hepatic circulation or through the blood stream. The serum concentration of calcitriol after ALF treatment was $57.5 \pm 18.5 \mathrm{pg} / \mathrm{ml}(95 \%$ CI $45.1 \sim 70 \mathrm{pg} / \mathrm{ml})$ (Table 4). When the achieved values of calcitriol after ALF treatment were incorporated into the regression equation of the relationship between calcitriol concentration and baseline FCA (Fig. 1A: $\mathrm{FCA}=9.7+0.22$ (calcitriol in $\mathrm{pg} / \mathrm{ml})$ ), the estimated $95 \% \mathrm{CI}$ of FCA in the ALF group was 19.6 25.1\%, while the actual value was $25.1 \sim 35.3 \%$. Because the actual value of FCA in the ALF group is higher than the estimated value, the enhanced FCA by ALF cannot be explained by the achieved calcitriol concentration. A study raised the possibility that the 25-hydroxylation in ALF is unnecessary for VDR activation, because the $\mathrm{OH}$-group in the $1 \alpha$ position is important for nuclear VDR activation, whereas the 25-OH group is of less importance [21]. Thus, it is possible that the high dose of ALF used in clinical settings $\left(1 \mu \mathrm{g} /\right.$ day equals $10^{-6}-\mathrm{M}$ exposure) binds to intestinal VDR directly, despite the observation that the affinity of ALF to VDR has been reported to be $1 / 1000$ of calcitriol [22]. Thus, the mechanisms of enhanced FCA in the ALF group may be explained by the direct effect of ALF and/ or converted calcitriol through the entero-hepatic circulation together with calcitriol from the blood stream. Further elucidation of the mode of action of ALF will be required.

The plain vitamin D3 treated group showed no significant increase in intestinal FCA. Because plain D is unable to bind to VDR [22], the compound needs to convert to calcitriol. As indicated in Table 4, a pharmacologic dose of plain vitamin D3 (800 IU is equivalent to $20 \mu \mathrm{g}$ ) increased serum concentrations of $25(\mathrm{OH}) \mathrm{D}$ and calcitriol. In addition to these vitamin D metabolites, other unmeasured metabolites such as 24,25 $(\mathrm{OH})_{2} \mathrm{D}$ or $1,24,25(\mathrm{OH})_{3}$ vitamin $\mathrm{D}$ are produced by the vitamin D catabolism pathway. As a whole, these metabolites might lead to overestimation of the serum calcitriol concentrations, as immunological cross-reaction between calcitriol and metabolites has been reported in calcitriol RIAs [17, 23, 24]. The marginal effect of plain vitamin $D 3$ on intestinal FCA is comparable to those in previous studies [25-28]. For example, Aloia et al. [27] and Hansen et al. [28] reported that plain vitamin D3 administration was not effective or induced only small increases in FCA in a high-dose group [28]. Recent reports indicated that CYP27B1 expression occurred in duodenal cells, suggesting that after 25-hydroxylation of plain vitamin D3 in the liver, $25(\mathrm{OH}) \mathrm{D} 3$ may be converted to calcitriol in the duodenum $[29,30]$. The other possible 
Table 5 Treatment effects on intestinal fractional calcium absorption (FCA)

\begin{tabular}{|c|c|c|c|c|c|c|c|}
\hline \multirow[t]{2}{*}{ Treatment } & \multirow{2}{*}{$\begin{array}{l}\text { Ca intake } \\
(\mathrm{mg})\end{array}$} & \multicolumn{3}{|c|}{ Baseline values } & \multicolumn{3}{|c|}{ At the end of the study } \\
\hline & & $\begin{array}{l}\mathrm{FCA} \\
(\%)\end{array}$ & $\begin{array}{l}\text { Abs } \\
(\mathrm{mg})\end{array}$ & $\begin{array}{l}\text { U-Ca } \\
(\mathrm{mg})\end{array}$ & $\begin{array}{l}\text { FCA } \\
(\%)\end{array}$ & $\begin{array}{l}\text { Abs } \\
(\mathrm{mg})\end{array}$ & $\begin{array}{l}\text { U-Ca } \\
(\mathrm{mg})\end{array}$ \\
\hline $\begin{array}{l}\text { ELD } \\
(n=9)\end{array}$ & 723 & $22.6 \pm 7.3$ & $163.6 \pm 52.5$ & $174.9 \pm 54.7$ & $33.7 \pm 4.6^{\mathrm{a}}$ & $243.4 \pm 33.3^{\mathrm{c}}$ & $230 \pm 64.4^{f}$ \\
\hline $\begin{array}{l}\text { ALF } \\
(n=9)\end{array}$ & 723 & $22.7 \pm 10.1$ & $164.4 \pm 73.3$ & $189.3 \pm 91.8$ & $30.2 \pm 9.5^{\mathrm{b}}$ & $218.3 \pm 68.8^{\mathrm{e}}$ & $263.0 \pm 81.3^{\mathrm{g}}$ \\
\hline $\begin{array}{l}\text { Plain vitamin } \mathrm{D}_{3} \\
(n=10)\end{array}$ & 723 & $21.5 \pm 7.6$ & $155.7 \pm 54.7$ & $179.3 \pm 70.9$ & $24.7 \pm 8.6$ & $178.3 \pm 62.3$ & $194.6 \pm 76.5$ \\
\hline $\begin{array}{l}\text { Control } \\
(n=10)\end{array}$ & 723 & $19.1 \pm 7.0$ & $138.3 \pm 50.8$ & $149.2 \pm 61.8$ & $20.4 \pm 6.5$ & $147.2 \pm 46.9$ & $143.0 \pm 63.4$ \\
\hline
\end{tabular}

The values of calcium intake, fractional calcium absorption (FCA), absorbed calcium (Abs) from the intestines, and urinary excretion of calcium (U-Ca) were calculated at the first visit (baseline) and at the day of the end of the study. The subjects were admitted and were provided exactly the same experimental diet, which contained $423 \mathrm{mg}$ /day of calcium, at the baseline and the end of the study. In addition to the experimental diet, ${ }^{44} \mathrm{Ca}$ was given orally as a $300-\mathrm{mg} \mathrm{CaCO}_{3}$ preparation. Therefore, the total amount of calcium intake at baseline and the end of the study was $723 \mathrm{mg} / \mathrm{day}$

Data are expressed as the mean $\pm \mathrm{SD}$. ANCOVA was used to evaluate $p$ values with factors for treatments and baseline fractional calcium absorption followed by Tukey's multiple comparison test

${ }^{\mathrm{a}} p<0.0001$ versus control and $p=0.0007$ versus Plain vitamin $\mathrm{D}_{3}$

${ }^{\mathrm{b}} p=0.0047$ versus control

${ }^{\mathrm{c}} p<0.0001$ versus control and $p=0.0007$ versus plain vitamin $\mathrm{D}_{3}$

${ }^{\mathrm{d}} p=0.0047$ versus control

${ }^{\mathrm{e}} p=0.0021$ versus control

${ }^{\mathrm{f}} p<0.0001$ versus control and $p=0.0041$ versus plain vitamin $\mathrm{D}_{3}$

Abbreviations: Ca, calcium; ELD, eldecalcitol; ALF, alfacalcidol; FCA, fractional Ca absorption rate; Abs, absorbed Ca; U-Ca, urinary Ca excretion

explanation for the poor FCA response to plain vitamin D3 treatment is that plain vitamin D3 can only stimulate FCA once a threshold serum concentration of calcitriol is achieved. The serum calcitriol increased to 63.6 from $46.6 \mathrm{pg} / \mathrm{mL}$ in the plain vitamin D3 group (Table 4). When this change is

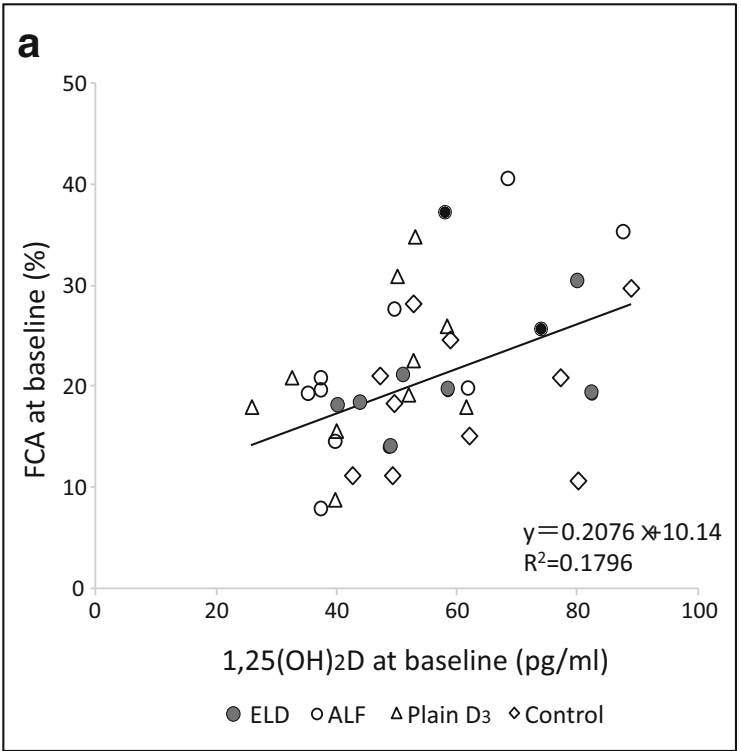

Fig. 1 Relationship between serum concentration of calcitriol and fractional calcium absorption (FCA) at baseline (a) and after the 4-week treatment (b). A significant correlation between them was observed at incorporated into the regression equation between FCA and calcitriol at baseline (Fig. 1A), the expected FCA in the plain vitamin D3 group is $23.3 \%$, which is similar to the actual value $(24.7 \%)$. Therefore, the stimulation of FCA by plain vitamin D3 appears to require a dose larger than 800 IU. In

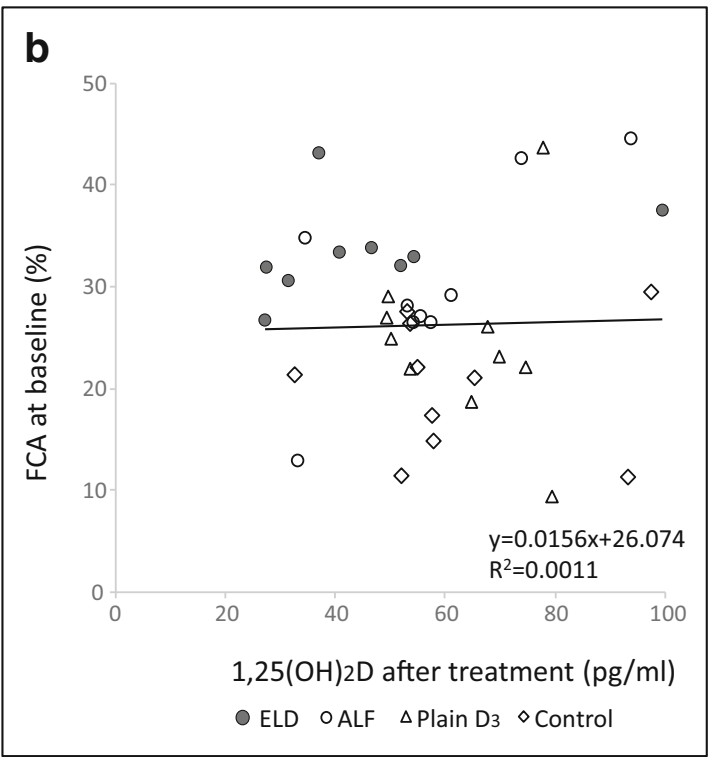

baseline $(p=0.0056)$ but not after treatment $(p=0.8437)$. ELD, eldecalcitol; ALF, alfacalcidol 
addition, although approximately $40 \%$ of the present population had a mild vitamin D insufficiency at baseline, all participants in the plain vitamin D3 treated group achieved serum concentration of $25(\mathrm{OH})$ vitamin D greater than $20 \mathrm{ng} / \mathrm{ml}$, suggesting that all subjects receiving plain D3 resolved their vitamin $\mathrm{D}$ insufficiency. Taken together, we presume that 800 IU of plain vitamin D3 administration is insufficient to induce significant enhancement of intestinal calcium absorption.

The effects of vitamin D3 compounds on serum parameters in the present study were similar to those in previous studies: ELD reduced calcitriol and bone resorption marker concentrations and ALF reduced parathyroid hormone concentration [31, 32]. We did not measure the bone formation marker, because in a previous study it did not change after 1 month of ELD treatment [32]. These metabolic changes after administration of vitamin D3 compounds may affect the concentrations of vitamin D metabolites and binding affinity to vitamin D binding protein. In a previous study, the potency of parathyroid hormone secretion in ELD-treated parathyroid cells was abolished when the cells were incubated with serum and stimulated when they were incubated without serum, suggesting that high binding affinity of ELD to DBP can be attributed to its weak ability to reduce parathyroid hormone secretion [33].

In this study, two patients dropped out, but their decision was not associated with drug-specific adverse events. In addition, no subject had hypercalcemia. Thus, there was sufficient tolerability in all treatment groups.

The present study has several limitations. The first is the limited number of subjects, which may have contributed to the lack of statistical power. As indicated in the methods section, we performed a power calculation to achieve significant differences in FCA measurements among the treatment groups. The second limitation was the short treatment duration, which was not equivalent to clinical osteoporosis treatment, because a longer term of treatment may induce adaptive changes in calcium absorption. In addition, the calcium absorption varied according to the baseline calcium nutrition of the participants. We did not adapt the calcium nutrition to the same amount of calcium during the study period. Thus, the absence of calcium adaptation during the study period may have produced the variations in the FCA. However, the habitual calcium intakes of the participants were within a narrow range, and we served the same diet on the test day to all participants. Thus, we conclude that differences in the calcium nutrition were not likely to produce significant variation in FCA. These potential effects require further clarification.

In conclusion, oral administration of ELD and ALF increased intestinal calcium absorption, likely by directly stimulating VDRs in the intestine. However, oral administration of plain vitamin D3 did not stimulate FCA, probably because the intestine lacks an activation system for the ingested plain vitamin D3 or participants received an insufficient dose of this compound, judging from the post-treatment calcitriol concentration. Our findings may help to explain the more beneficial effect of ELD and ALF on bone as compared to that of plain vitamin D3.

Acknowledgments We thank the study patients for their participation.

Funding information The study was funded by Chugai Pharmaceuticals Co., Ltd.

\section{Compliance with ethical standards}

Conflict of interest Masataka Shiraki received personal fees from Chugai Pharmaceutical Co., Ltd. during the study and advisory fees from Teijin Pharma Co. and Asahi-kasei Pharma Co. Kazuhiro Uenishi received personal fees from Chugai Pharmaceutical Co., Ltd. during the study. Makio Tokiwa is an employee of IDD Co. Shigeaki Kato declares no conflict of interest.

Open Access This article is distributed under the terms of the Creative Commons Attribution-NonCommercial 4.0 International License (http:// creativecommons.org/licenses/by-nc/4.0/), which permits any noncommercial use, distribution, and reproduction in any medium, provided you give appropriate credit to the original author(s) and the source, provide a link to the Creative Commons license, and indicate if changes were made.

\section{References}

1. Ohta H, Uenishi K, Shiraki M (2016) Recent nutritional trends of calcium and vitamin D in East Asia. Osteoporos Sarcopenia 2(4): 208-213. https://doi.org/10.1016/j.afos.2016.08.002

2. Uenishi K, Ishida H, Kamei A, Shiraki M, Ezawa I, Goto S, Fukuoka H, Hosoi T, Orimo H (2001) Calcium requirement estimated by balance study in elderly Japanese people. Osteoporosis Int 12(10):858-863. https://doi.org/10.1007/s001980170037

3. Ohta H, Uemura Y, Nakamura T, Fukunaga M, Ohashi Y, Hosoi T, Mori S, Sugimoto T, Itoi E, Orimo H, Shiraki M, Adequate Treatment of Osteoporosis (A-TOP) Research Group (2014) Serum 25-hydroxyvitamin D level as an independent determinant of quality of life in osteoporosis with high risk of fracture. Clin Ther 36(2):225-235. https://doi.org/10.1016/j.clinthera.2013.12.007

4. Tanaka S, Kuroda T, Yamazaki Y, Shiraki Y, Yoshimura N, Shiraki M (2014) Serum 25-hydroxyvitamin D below $25 \mathrm{ng} / \mathrm{mL}$ is a risk factor for long bone fracture comparable to bone mineral density in Japanese postmenopausal women. J Bone Miner Metab 32(5):514 523. https://doi.org/10.1007/s00774-013-0520-3

5. Norman AW (1990) Intestinal calcium absorption: a vitamin Dhormone-mediated adaptive response. Am J Clin Nutr 51(2):290 300

6. Nordin BE, Morris HA (2011) Recalculation of the calcium requirement of adult men. Am J Clin Nutr 93(2):442-445. https://doi.org/ 10.3945/ajen.110.004382

7. Gallagher JC, Riggs BL, Eisman J, Hamstra A, Arnaud SB, DeLuca HF (1979) Intestinal calcium absorption and serum vitamin D metabolites in normal subjects and osteoporotic patients: effect of age and dietary calcium. J Clin Invest 64(3):729-736. https://doi.org/ 10.1172/JCI109516

8. Howard A, Legon S, Walters JRF (1993) Human and rat intestinal plasma membrane calcium pump isoforms. Am J Physiol Gastrointest Liver Physiol 265:G917-G925 
9. Balesaria S, Sangha S, Walters JRF (2009) Human duodenum responses to vitamin D metabolites of TRPV6 and other genes involved in calcium absorption. Am J Physiol Gastrointest Liver Physiol 297(6):G1193-G1197. https://doi.org/10.1152/ajpgi. 00237.2009

10. Saito H, Harada S (2014) Eldecalcitol replaces endogenous calcitriol but does not fully compensate for its action in vivo. $\mathrm{J}$ Steroid Biochem Mol Biol 144:189-196. https://doi.org/10.1016/ j.jsbmb.2013.11.013

11. Brown AJ, Ritter CS (2011) The vitamin D analog $1 \alpha, 25-$ dihydoxy-2 $\beta$-(2-hydroxypropyloxy) vitamin D3 (eldecalcitol) is a potent regulator of calcium and phosphate metabolism. Calcif Tissue Int 89(5):372-378. https://doi.org/10.1007/s00223-0119528-7

12. Uenishi K, Fujita T, Ishida H, Fujii Y, Ohue M, Kaji H, Hirai M, Kakumoto M, Abrams SA (2010) Fractional absorption of active absorbable algal calcium (AAACa) and calcium carbonate measured by a dual stable-isotope method. Nutrients 2(7):752-761. https://doi.org/10.3390/nu2070752

13. Eastell R, Vieira NE, Yergey AL, Riggs BL (1989) One-day test using stable isotopes to measure true fractional calcium absorption. J Bone Miner Res 4(4):463-468. https://doi.org/10.1002/jbmr. 5650040403

14. Kumari M, Khazai NB, Ziegler TR, Nanes MS, Abrams SA, Tangpricha V (2010) Vitamin D-mediated calcium absorption in patients with clinically stable Crohn's disease: a pilot study. Mol Nutr Food Res 54(8):1085-1091. https://doi.org/10.1002/mnfr. 200900351

15. FRAX(R) Japanese edition. https://www.shef.ac.uk/FRAX/index. aspx?lang=jp

16. Patterson KY, Veillon C, Hill AD, Moser-Veillon PB, O'Haver TC (1999) Measurement of calcium stable isotope tracers using pool plasma ICP-MS. J Anal At Spectrom 14(11):1673-1677. https:// doi.org/10.1039/A900677J

17. Fraser WD, Durhan BH, Berry JL, Mawer EB (1997) Measurement of plasma 1,25 dihydroxyvitamin D using a novel immunoextraction technique and immunoassay with iodine labeled vitamin D tracer. Ann Clin Biochem 34(6):632-637. https://doi.org/ 10.1177/000456329703400606

18. Roughead ZK, Johnson LK, Lykken GI, Hunt JR (2003) Controlled high meat diets do not affect calcium retention or indices of bone status in healthy postmenopausal women. J Nutr 133(4):1020-1026

19. Tahiri M, Tressol JC, Arnaud J, Bornet FR, Bouteloup-Demange C, Feillet-Coudray C, Brandolini M, Ducros V, Pépin D, Brouns F, Roussel AM, Rayssiguier Y, Coudray C (2003) Effect of shortchain fructooligosaccharides on intestinal calcium absorption and calcium status in postmenopausal women: a stable-isotope study. Am J Clin Nutr 77(2):449-457

20. Heaney RP, Recker RR, Stegman MR, Moy AJ (1989) Calcium absorption in women: relationships to calcium intake, estrogen status, and age. J Bone Miner Res 4(4):469-475. https://doi.org/10. 1002/jbmr.5650040404

21. Norman AW, Adams D, Collins ED, Okamura WH, Fletterick RJ (1999) Three-dimensional model of the ligand binding domain of the nuclear receptor for 1alpha, 25-dihydroxy-vitamin D3. J Cell
Biochem 74(3):323-333. https://doi.org/10.1002/(SICI)10974644(19990901)74:3<323::AID-JCB2>3.0.CO;2-V

22. Simpson RU, Franceschi RF, DeLuca HF (1980) Characterization of a specific, high affinity binding macromolecule for $1 \alpha, 25$ dihydroxyvitamin D3 in cultured chick kidney cells. J Biol Chem 255(21):10160-10166

23. Lips P (2007) Review: relative value of $25(\mathrm{OH}) \mathrm{D}$ and $1,25(\mathrm{OH})_{2} \mathrm{D}$ measurements. J Bone Miner Res 22(11):1668-1671. https://doi. org/10.1359/jbmr.070716

24. Lai JK, Lucas RM, Clements MS, Harrison SL, Banks E (2010) Assessing vitamin D status: pitfalls for the unwary. Mol Nutr Food Res 54(8):1062-1071. https://doi.org/10.1002/mnfr.200900468

25. Gallagher JC, Yalamanchili V, Smith LM (2012) The effect of vitamin D on calcium absorption in older women. J Clin Endocrinol Metab 97(10):3550-3556. https://doi.org/10.1210/jc.2012-2020

26. Gallagher JC, Jindal PS, Smith LM (2014) Vitamin D does not increase calcium absorption in young women: a randomized clinical trial. J Bone Miner Res 29(5):1081-1087. https://doi.org/10. 1002/jbmr.2121

27. Aloia JF, Dhaliwal R, Shieh A, Mikhail M, Fazzari M, Ragolia L, Abrams SA (2014) Vitamin D supplementation increases calcium absorption without a threshold effect. Am J Clin Nutr 99(3):624 631. https://doi.org/10.3945/ajcn.113.067199

28. Hansen KE, Johnson RE, Chambers KR, Johnson MG, Lemon CC, Vo TNT, Marvdashti S (2015) Treatment of vitamin D insufficiency in postmenopausal women. A randomized clinical trial. JAMA Intern Med 175(10):1612-1621. https://doi.org/10.1001/ jamainternmed.2015.3874

29. Gawlik A, Gepstein V, Rozen N, Dahan A, Ben-Yosef D, Wildbaum G, Verbitsky O, Shaoul R, Weisman Y, Tiosano D (2015) Duodenal expression of 25 hyroxyvitamin D3-1 $\alpha$ hydroxylase is higher in adolescents than in children and adults. $\mathrm{J}$ Clin Endocr Metab 100(10):3668-3675. https://doi.org/10.1210/jc. 2015-1483

30. Torremade N, Bozic M, Goltzman D, Fernandez E, Valdivielso JM (2017) Effects of the administration of $25(\mathrm{OH})$ vitamin D3 in an experimental model of chronic kidney diseases in animals null for 1-alpha-hydroxylase. PLoS One 12(1):e0170654. https://doi.org/ 10.1371/journal.pone.0170654

31. Matsumoto T, Miki T, Hagino H, Sugimoto T, Okamoto S, Hirota T, Tanigawara Y, Hayashi Y, Fukunaga M, Shiraki M, Nakamura T (2005) A new active vitamin D, ED-71, increases bone mass in osteoporotic patients under vitamin D supplementation: a randomized, double-blinded, placebo-controlled clinical trial. J Clin Endocrinol Metab 90(9):5031-5036. https://doi.org/10.1210/jc. 2004-2552

32. Matsumoto T, Takano T, Yamakido S, Takahashi F, Tsuji N (2010) Comparison of the effects of eldecalcitol and alfacalcidol on bone and calcium. J Steroid Biochem Mol Biol 121(1-2):261-264. https://doi.org/10.1016/j.jsbmb.2010.03.035

33. Ritter CS, Brown AJ (2011) Suppression of PTH by the vitamin D analog eldecalcitol is modulated by its high affinity for the serum vitamin D-binding protein and resistance to metabolism. J Cellular Biochemist 112:1348-1352 